\title{
ELLA: SUS MUCHAS CARAS. \\ TRADUCIR POESÍA AUTÓCTONA \\ DESDE TEORÍAS FEMINISTAS Y POSCOLONIALES
}

\author{
Lidoly Chávez
}

McGill University

Department of Languages, Literatures and Cultures

\section{RESUMEN}

La traducción al español de la obra de Louise Halfe es apenas un punto de partida en la reflexión sobre la insuficiente circulación de literaturas autóctonas femeninas en las Américas. Con el traspaso lingüístico de un texto como Blue Marrow, se suscita una triple revalorización cultural de creadores "periféricos" a los que aún el canon literario hegemónico no sitúa en su justo lugar: el sujeto indígena, la mujer, la traductora. Una traducción basada en teorías poscoloniales y feministas extiende la vocación subversiva de Halfe para enriquecer las culturas hispanoamericanas con el aporte de nuevos referentes y estrategias disruptivas de la lengua dominante, así como de una profunda conciencia sobre la mujer en los procesos coloniales y en la transmisión de la memoria.

\section{PALABRAS CLAVE}

Poscolonial, Feminista, Traducción, Literatura canadiense, Indígena

\section{ABSTRACT}

The translation of Louis Halfe's work into Spanish is only the first step in reflecting on the limited circulation of female indigenous literatures in the Americas. Through the linguistic transfer of her text Blue Marrow, we see a cultural revision of "peripheral" creators - the indigenous subject, the woman, the translator - who are now relegated to a secondary rank by the hegemonic literary canon. A translation based on postcolonial and feminist theories, however, allows new audiences to witness Halfe's subversive spirit, as such a text provides Hispanic American cultures with new experiences and strategies that disturb the dominant language. Halfe's literature also contributes to a deepening 
awareness about the role of women in the colonial context and the transmission of memory.

KEY WORDS

Postcolonial, Feminist, Translation, Canadian literature, First Nations 
Desde el momento en que la escritora canadiense Louise Halfe se pronuncia culturalmente para reafirmar su identidad de mujer autóctona como producto híbrido, se abre la puerta a una reflexión sobre el propio acto de traducción de su obra. La autora de origen cree $^{1}$ iza un activismo político que pretende, desde la poesía, subvertir la historia canonizada desde una perspectiva blanca, masculina y hegemónica. De ahí que a la hora de leer y recodificar su obra en español - pasos indisolubles y hasta simultáneos en la práctica traductora - valga la pena extender las rebeldes intenciones del texto original hasta lectoras y lectores hispanoamericanos, indiscutiblemente marcados por las tensiones y los efectos del colonialismo en las Américas.

Tanto las escuelas traductológicas poscoloniales como las feministas pueden enriquecer el traspaso lingüístico de un texto que, por una parte, profundiza en la inestabilidad de los límites culturales, el mestizaje resultante de la zona de contacto colonial y, por la otra, pone de relieve el papel femenino como eje de ese mestizaje y de la recuperación de la memoria.

En las páginas que siguen, pues, quisiera presentar la obra de Halfe a los receptores potenciales de su traducción, y reflexionar sobre las cualidades más relevantes de su creación literaria que justifican un posicionamiento político y de género en su traducción del inglés al español. Voy a detenerme, particularmente, en su poemalibro Blue Marrow.

1 En este texto trabajo la denominación "cree" (sin ningún destaque) al referirme a la etnia autóctona norteamericana.

\section{POESÍA TESTIMONIAL: VIVENCIA Y LETRA}

De modo general, puede decirse que la obra de Louise Halfe es heredera de la cosmovisión oral que confirma, en gran parte de las literaturas autóctonas canadienses, el impacto de la experiencia humana sobre la adquisición de conocimientos y la comunicación. Como explica la estudiosa Penny Petrone en su texto Native Literature in Canada. From the Oral Tradition to the Present, las poéticas indígenas conciben el entorno existencial como "both ritualistic and historical, contemporary and ancient" [ceremonial e histórico, actual y antiguo] (Petrone, 1990: 5).

El contexto en el que estas culturas han vivido no puede quedar de lado desde ningún proyecto de lectura - $\mathrm{y}$ la traducción es uno de ellos-que comparta su agenda ideológica. Halfe, en particular, retoma las inquietudes colectivas de la etnia cree, que a partir de la colonización fue forzada a reinventarse, a "traducirse" a los códigos blancos, de ahí que hallemos en ella una sólida impronta de los actos extratextuales que definieron la hibridación: "What has been experienced over the ages mystically and communally — with individual experiences fitting within that overarching pattern $[\ldots]$ form the basis for tribal aesthetics and therefore of tribal literatures" [Lo que se ha vivido a lo largo de tantos años de manera mística y comunitaria (...) define las bases de la estética tribal y, por consiguiente, de las literaturas tribales] (Gunn Allen, 1989: 4).

En esta dirección, Shelley Stigter, en su estudio sobre la poesía de Halfe, así como del también poeta cree Gregory Scofield, apunta "Not 
only is knowledge of the Cree and English languages required to participate in Native literatures, but the cultural context surrounding these language is also needed" [Para participar en las literaturas nativas no basta saber cree e inglés, sino hace falta asimismo conocer el contexto cultural que rodea estas lenguas] (Stigter, 2006: 50).

Al emplear dos lenguas fundamentales (cree e inglés) en su creación literaria, y al integrar diversos códigos expresivos que evidencian los sustratos culturales que la nutren, Halfe da cuenta de una comunidad dividida entre su identidad ancestral y el impacto colonial. Junto a esto, su doble condición de mujer y de nativa ${ }^{2}$ — con todas sus connotaciones históricas y sociales - serán motivos centrales de sus tres libros.

Pese a tratarse de una poesía en ocasiones hermética, de escasas concesiones con el mercado, las tres obras de Halfe han sido reconocidas por varios premios literarios. Su primer poemario, Bear Bones and Feathers, publicado por Coteau Books en 1994, obtuvo el Canadian Peoples Poet Award y fue finalista del reconocimiento Spirit of Saskatchewan; el segundo, Blue Marrow, fue nominado al premio de Gobernador General, al Pat Lowther Award, al premio de poesía de Saskatchewan y al del Libro del Año de Saskatchewan en 1998.

En 2005 Halfe fue laureada como Nueva Poeta de Saskatchewan, y su tercer cuaderno, The Crooked Good, publicado en 2007, obtuvo

2 Aunque no se use con demasiada frecuencia en el contexto hispánico para aludir a los pueblos indígenas, utilizo aquí el término "nativa(o)" como sinónimo de aborigen, por la extensa utilización del equivalente Native en el caso de Estados Unidos y Canadá. el Saskatoon Book Award y el First Peoples Publishing Award. No obstante, su literatura ha sido escasamente traducida y en América Latina es casi desconocida. Además de la pertinencia en el continente de obras testimoniales sobre la experiencia colonial y de sus valores literarios e ideológicos, en especial el poema-libro Blue Marrow demuestra sus conexiones con el universo hispanoamericano ya desde la obra que la autora toma como epígrafe: un fragmento de "La insepulta de Paita", elegía de Pablo Neruda dedicada a Manuela Sáenz.

El primer cuaderno de Halfe, Bear Bones and Feathers, se aproxima en setenta y ocho poemas al patrimonio cree: los recuerdos hogareños, las relaciones de parentesco, usos y costumbres, tradiciones espirituales y míticas, pero otorga especial énfasis a la inserción de este patrimonio en la vida moderna y a la desarticulación de la familia nativa como huella de una violencia que se ha reproducido desde la conquista. A través de personajes de ayer y hoy, en disímiles tonos y formas — desde la prosa poética hasta el verso rimado- - las páginas de Halfe ahondan en saldos históricos como el alcoholismo, la violencia doméstica, la desmoralización, los crímenes sexuales y los homicidios.

Por encima de todo, sin embargo, a la autora le interesa mostrar un patrimonio que aunque dista de la perfección, es tangible. Extrae la cultura cree de una vitrina de museo para exponerla como una realidad de hoy, que pertenece al espacio canadiense actual tanto como la institucionalidad blanca que la invisibiliza. La memoria coexiste con la tecnología contemporánea y disecciona, desde la experiencia 
vital, los mecanismos de preservación de los valores tradicionales en un entorno donde los productos culturales superponen tiempos y espacios: "Oh yeah, for school I had your bannock and fried rabbit. / I'd eat it kîmôc in the bathroom so the white kids / wouldn't laugh at me. Oh, it was good. So good. // You want some tea and a cigarette?" [Ay sí, llevaba a la escuela tu bannock y conejo frito. / Comía kîmôc en el baño para que los chicos blancos / no se burlaran de mí. Ay, sí que era sabroso. Tan sabroso. // ¿Quieres un poco de té y un cigarrillo?] (Halfe, 1994: 45). "Pemmican" y "croissants", "powwow" y "cruise ship", "moccasins" y "platform shoes" coinciden en la representación de colectivos híbridos que no escapan a su presente. A sus continuas reflexiones sobre la lengua impuesta, Halfe añade un cuestionamiento de los valores dominantes expresados en ella: "The doctor said it was a / broken/ hymen. // She didn't know that / hymns were sung between / her legs" [El médico dijo que el hymen / se había / roto. // Ella no sabía que / se cantaban himnos entre / sus piernas] (Halfe, 1994: 48).

Una voluntad crítica permeada de humor subvierte así los paradigmas y estereotipos que se ciernen sobre la condición femenina al tiempo que reflexiona sobre el impacto de las instituciones coloniales - las reservas, las escuelas residenciales y la Iglesia - sobre la mujer autóctona.

A partir de sus recuerdos y vivencias como trabajadora social, en Bear Bones and Feathers Halfe inserta imágenes chocantes — violentas o escatológicas - y zonas oscuras que llegan a ser perturbadoras. Se apropia del género poético para reafirmar su alteridad y desarticula el inglés dando cuenta del sustrato cree a través de palabras en su idioma. Para Shelley Stigter, este recurso es una vía para involucrar más a los lectores con el texto en tanto propicia la conciencia de la retroalimentación entre las culturas dominante y dominada, mientras remite a la estrategia oral de la alternancia de códigos. "In a literary sense, the code-switching within the poetry by these Aboriginal authors [Halfe y Scofield] works in the same manner as conversational strategies: they are representative of crossing cultural boundaries" [En sentido literario, el cambio de código en la poesía de estos autores aborígenes funciona de la misma manera que las estrategias conversacionales: representan el traspaso de barreras culturales] (Stigter, 2006: 50). De modo que en la mezcla de lenguas radica, además, la remisión a la oralidad, vital para una cultura ágrafa que tiene en la narración oral y en la figura del cuentacuentos sus vías tradicionales de trasmisión de conocimientos.

Blue Marrow, salido a la luz cuatro años después de Bear Bones and Feathers, representa, más que una continuación, una profundización sustancial de los rasgos estilísticos presentados por Halfe en su primer cuaderno. Una fuerte impronta oral lograda por medio de aliteraciones y fórmulas fijas, la desarticulación de la sintaxis del inglés, el uso de la ironía y de imágenes complejas $\mathrm{y}$ oscuras son recursos que abundan en el segundo cuaderno.

Desde el punto de vista estructural, Halfe también propone una ruptura mucho más radical con los paradigmas de la literatura occidental contemporánea, que en general entiende el género poético como construcciones breves. En cuanto a 
las voces líricas, si en Bear Bones and Feathers los personajes tomaban la palabra en poemas separados, marcando con mayor claridad las unidades enunciativas, en Blue Marrow numerosas voces aparecen amalgamadas en un solo poema extenso: es una sola historia que, como el espacio canadiense, deviene escenario de confluencias, zona de contacto colonial con diversos actores en tensión. La hibridez, entonces, asciende un peldaño en este libro, dinamizando aún más los contrastes y simbiosis al presentar "multiple speakers whose clashing, intermittent language transgresses the authority of the conventionally bounded text" [múltiples hablantes cuyas lenguas contrapuestas e intermitentes transgreden la autoridad del texto cerrado convencional] (Cook, 2000: 86).

Blue Marrow enuncia las vivencias del pueblo cree desde las primeras décadas del comercio de pieles hasta nuestros días, a través del contacto entre la narradora - a quien podemos identificar con la propia Halfe por los datos autobiográficos del texto- ${ }^{3}$ y los espíritus de sus abuelas, que descienden a dictar sus memorias, personales y comunitarias. A diferencia de Bear Bones and Feathers donde, según Méira Cook (2000: 87), la voz narrativa "traduce" un dictado del universo, en Blue Marrow hay un énfasis en el paisaje humano de la historia y se concede la voz a las antecesoras que yacen "tongueless in the earth" [deslenguadas en la tierra] (Halfe, 1998: 6).

3 Halfe cita los nombres de sus abuelas reales en el poema, lo que confiere valor testimonial al texto: "Adeline Cardinal, Emma Woods, Sara Cardinal Bella Shirt, Nancy Gladue, Fanny Sunchild, Round Face Woman [...]". (Halfe, 1998: 3). Además, incorpora fotos familiares de sus propios abuelos.
Este relato de las abuelas, que transgreden el aislamiento de la muerte para conectarse con el presente, evoca las prácticas ancestrales de narración colectiva y propicia confluencias de lenguas, tiempos y puntos de vista. Blue Marrow es una obra ambiciosa que desarticula el relato convencional para reconstruir una versión alternativa, una historia inclusiva que da voz a quienes forman parte de ella, en especial a los aborígenes relegados al silencio porque, como culturas orales, durante la colonia no dejaron documentos escritos desde su perspectiva.

El texto de Halfe se muestra como historia travestida de poema que funde la narrativa con el teatro y que, además, dialoga intertextualmente con tradiciones discursivas crees, relatos bíblicos y patrones cristianos de confesión y oración.

La conexión entre Bear Bones and Feathers y Blue Marrow resulta evidente por un fondo cultural común pero, en especial, por una anécdota que conecta el final del primer libro con el inicio del segundo. Se trata del recuento de un sueño donde la narradora se ve a sí misma reparando la cabaña de su infancia con papeles y libros, y que puede interpretarse como la responsabilidad intelectual de la poeta en la reconstrucción de la memoria (Halfe, 1994: 127; 1998: 1).

\section{LA MUJER COMO CENTRO DEL UNIVERSO POÉTICO}

Como he comentado, la mujer aborigen es tema central de Blue Marrow, con un rostro moldeado por su historia común-y, al mismo tiempo, muchos ("She came in a Vision, flipped many faces [...] She's the burnt rose of autumn, a 
blue-winged warbler. The awakened river flanked in every woman, rolling pebbles over and over till stone eggs are left") [Ella llegó en una Visión, volteaba sus muchas caras (...) Es la rosa quemada del otoño, una reinita aliazul. El río despierto contenido en cada mujer, guijarros que ruedan y ruedan hasta que sólo quedan huevos de piedra] (Halfe, 1998: 86). La condición femenina se vuelve en Halfe eje central de su cosmos porque, por una parte, Blue Marrow funciona como acto de redención de la memoria y de la palabra de quienes nunca la tuvieron $\mathrm{y}$, por otra, no menos relevante, porque homologa el evento discursivo con la concepción y, en su cualidad subversiva, a contracorriente, con el pecado de Eva ("I feed him my Apple. // My printer sins" [Le doy mi manzana. // Mi impresora peca]) (Halfe, 1998: 31).

Al publicar el libro, los editores de McClelland afirmaban: "Grandmothers both actual and spiritual are prominent in this moving tribute to Native female strength [...]" [Tanto las abuelas reales como las espirituales sobresalen en este conmovedor tributo a la fuerza de las mujeres nativas] (Halfe, 1998: nota de contracubierta). La figura de la abuela, su maternidad duplicada, ensalza la triple condición creativa de la mujer en el seno de la sociedad cree. La maternidad, el oficio de curandera y el de narradora oral resaltan de tres maneras su papel como dadora de vida. Shannon Smith ilustra esta coincidencia de funciones: "Storytelling doesn't heal a broken bone or soothe a cough; but it does hold the power to mend the spirit, strengthen and empower" [La narración oral no cura un hueso roto ni alivia la tos; pero sí puede sanar el espíritu, darle fuerza y poder] (Smith, s/f, en línea). La figura de la abuela remite al ciclo de la descendencia y, por consiguiente, de la pervivencia de la tradición y la memoria: "Grandmother dances at Midnight. Grandmother Moon, my Shadow dreams the dark. // Grandmother, the Woman in Me" [Abuela danza a Medianoche. Abuela Luna, mi Sombra sueña la oscuridad. // Abuela, la Mujer en Mí] (Halfe, 1998: 90).

Desde una reflexión antropológica, Geraldine Manossa resalta:

Within Cree culture, the Moonlodge ceremony celebrates womanhood. Women gather together during their menstruation to pray and to honour themselves as women, as life givers. Within the same context a woman's menstruation is referred to as "moon-time" or a woman is experiencing her "moon." Ojibway and Cree cultures are very similar in this teaching; when a woman is on her "moon," the presence of a grandmother-spirit is with her. Odawa/Ojibway elder, Edna Manitowabi told me that a woman's moon-time is a sacred time; the woman's spiritual power is strong because of the spiritual presence of the grandmother. Thus, a woman's moon-time is an occasion for the woman to rest, look inward, question her life's journey and meditate because she has the wisdom, intuition and guidance of a grandmother-spirit. [En la cultura cree, la ceremonia de la cabaña lunar es una celebración de la condición femenina. Las mujeres se reúnen durante su período menstrual para orar y honrarse a sí mismas como mujeres, como dadoras de vida. En el mismo contexto, las personas se refieren a la menstruación como "tiempo lunar" o dicen que una mujer está en su "luna". Las culturas cree y ojibway se parecen en estos principios; cuando una mujer está en su "luna", el espíritu de una abuela la acompaña. Edna Manitowabi, una anciana odawa/ojibway, me 
contó que el "tiempo lunar" de una mujer es sagrado; el poder espiritual de la mujer se fortalece gracias a la presencia espiritual de la abuela. De ese modo, el tiempo lunar de una mujer es un período para que la mujer descanse, reflexione, cuestione el viaje de su vida y medite, porque ella tiene la sabiduría, la intuición y la guía del espíritu de una abuela] (Manossa, 2002: 33-34).

A partir de este comentario casi podríamos afirmar que la condición femenina motiva la existencia del poema de Halfe. El recuento de su vida y la de su pueblo parecen nacer de la "luna" (léase feminidad) y la mirada interior de la autora.

Una huella en el cuerpo femenino de la voz lírica expresa su capacidad discursiva y abre el camino de homenaje a sus antecesoras: "On my left breast was a hoofprint. It disappeared when I began the walk for them: Adeline Cardinal. Emma Woods. Sara Cardinal. Bella Shirt. Nancy Gladue" [En mi seno izquierdo había una huella de casco. Desapareció cuando eché a andar por ellas: Adeline Cardinal. Emma Woods. Sara Cardinal. Bella Shirt. Nancy Gladue] (Halfe, 1998: 3). Ésta es, simultáneamente, marca y cicatriz que, según Cook (2000: 88), identifica a la narradora como mujer y como poeta. Al igual que en el ciclo de la descendencia, la mujer toma el lugar de sus antepasadas, generación tras generación, en la transmisión de la memoria. La voz de la nieta expresa: "Grandmothers hold me. I must pass all that I possess, / every morsel to my children. These small gifts/ to see them through life. Raise my fist. Tell the story" [Las abuelas me sostienen. Tengo que pasar todo lo que tengo, / cada porción a mis hijos. Estos pequeños regalos / para verlos a lo largo de la vida. Levantar mi puño. Contar la historia] (Halfe, 1998: 5).

Blue Marrow, además, se conecta con la angustia de la mujer a través de la violencia de género que se superpone a la violencia colonial por medio de la representación de los atributos de maternidad arrancados. El poema se erige entonces como un desagravio ante esas identidades femeninas ultrajadas. Según expone David Gaertner:

\footnotetext{
"Since the breast has been 'scalped' or violently removed from the body, we might infer the same for the womb, represented here as a 'medicine bag.' The image of the womb in this brutal context allows us to infer that it is out of the pain of these women that healing is born" [Como el seno ha sido "arrancado" o extraído violentamente del cuerpo, podemos deducir que lo mismo ha ocurrido con la matriz, aquí representada como "bolsa medicinal". La imagen de la matriz en este contexto brutal nos hace inferir que es del dolor de esas mujeres que nace la sanación] (Gaertner, 2007: 30-31).
}

De modo semejante, el tráfico de pieles puede leerse como metáfora del tráfico de la mujer. Además de frotar su propia piel con ceniza para blanquearse y acercarse al paradigma del prestigio evocando el curtido de los cueros comerciales ('I've scrubbed with ashes, / still my skin is baked") [Me he frotado con ceniza, / pero mi piel sigue quemada] (Halfe, 1998: 53), la nativa - cuyo padre la entrega a un traficante blanco a cambio de mercancías y relaciones de negocioreconoce abiertamente: "I, his youngest [...] I became the trade" [Yo, su hija menor (...) me volví el negocio] (Halfe, 1998: 51). 
Basado en el escenario histórico canadiense de relaciones interétnicas, Blue Marrow toma como eje un episodio de pasiones y violencia donde la abuela amante de un factor británico es asesinada por éste después que los jesuitas la han maldecido. Halfe asocia simbólicamente el etnocidio con la condición femenina, por dos razones. La primera, porque la relación de poder se duplica en las asimetrías de los pares colonizador-colonizada y hombre-mujer; y la segunda, por el valor de la mujer como educadora, contadora de historias, transmisora de la memoria en el seno comunitario. Al asesinarla, no sólo hay violencia de género, sino se silencia una cultura. ${ }^{4}$ En los últimos años, cuando las estadísticas de mujeres autóctonas asesinadas o desaparecidas se han disparado de manera alarmante en Canadá, ${ }^{5}$ la poesía de Halfe multiplica su elocuencia como instrumento documental y de denuncia.

La fusión de los personajes femeninos (pasados y presentes), la noción de ciclo, la impronta repetitiva de la oralidad y la multiplicidad de discursos, destierran toda linealidad temporal del poema. Lejos de una lógica argumental 4 A propósito del papel femenino en la trasmisión de valores tradicionales y aun como personajes míticos, las diosas madres de las culturas, Shannon Smith plantea: "Women were seen as keepers of the faith due to their responsibility and recollection within the oral tradition, but they were also featured in many creation myths as the life-giving deity" y reproduce las palabras de la maestra nativa Philomine Lakota: "I think that as women we are making a great contribution to restoring the protocols that were in place before the acculturation happened [...] That is, that women are sacred. They are lifegivers" (Smith, s/f, en línea).

5 Sobre este tema, véase, por ejemplo, los datos actualizados en el reportaje de Joanna Jolly, "El macabro misterio de las mujeres de Río Rojo del Norte", en BBC Mundo, 19 de abril de 2015: http:/www.bbc.co.uk/mundo/noticias/2015/04/150416 misterio_macabro_rio_rojo_finde_dv cronológica, Blue Marrow comienza in medias res e incorpora las digresiones del narrador oral, el recuento de un suceso desde varias perspectivas y, por consiguiente, el retorno a un mismo punto en el tiempo. El ciclo temporal se consuma cuando la nieta, una vez que ha escuchado a sus antecesoras, ejerce la palabra y, con ella, encarna a las abuelas en su propio ser: "Later, driving home, / I weave a story for my children [...] I tell them/ how my little children died wrapped/ in smallpox blankets [Luego, camino a casa, / entretejo una historia para mis hijos (...) Les cuento cómo mis hijos morían envueltos / en mantas de viruela]" (Halfe, 1998: 61-62). Presenciamos, de ese modo, cómo los tiempos se superponen.

En Blue Marrow la transmisión oral puede leerse además como una marca generacional. La poeta-narradora ${ }^{6}$ guarda un hueso bajo su almohada — "the jaw bone of elk lined with pearly teeth" [la mandíbula de alce con una fila de dientes perlados] (Halfe, 1998: 14) que, de acuerdo con Cook, al posibilitar la articulación del habla se convierte en guía y tótem de su acto narrativo como símbolo de la oralidad, al tiempo que, según Gartner, la "médula azul" del título puede interpretarse como metáfora de la tinta con la que la nieta plasma por escrito su nueva versión de la historia (Gaertner, 2007: 4). Su acto es, por consiguiente, un medio de lucha de las generaciones actuales: "My hunt is without a rifle, / without a net, / my bone/ filled with the fists of women / of the fur trade" [Mi caza es sin rifle, / sin red, / mis huesos van llenos de los puños de las mujeres / del tráfico de pieles] (Halfe, 1998: 12-13). 6 A partir de este momento me referiré al personaje de la nieta que transcribe, identificable con Halfe, como "poetanarradora”. 
De ese modo, además de la lengua inglesa, el acto de la escritura resulta ser otro de los legados coloniales de los que Halfe se apropia en un gesto calibanesco para redimir su identidad. "This translation of speech into writing is perhaps inevitable in the context of Western modes of production and reception, where poetry is typically communicated through the silent communion between the (absent) writer on one side of the page and the reader on the other" [Esta traducción del discurso a la escritura es quizás inevitable en el contexto de los modos occidentales de producción y recepción, en los que la poesía se comunica típicamente por medio de la comunión silenciosa entre el escritor (ausente) de un lado de la página y el lector en la otra] (Cook, 2000: 86).

Halfe no desnaturaliza su posición híbrida de enunciación como herencia de la zona de contacto, sino rearticula los discursos en función de su proyecto político. Aunque imita los coloquialismos y las fórmulas del discurso oral, el empleo de numerosos recursos tipográficos como alternancia de cursivas y redondas y distintos grados de sangría para marcar los bloques de texto son elementos que refuerzan la cualidad escrita y, digamos, visual, del texto. La obra demuestra conciencia sobre su propia naturaleza lingüística, así que toma un carácter metaliterario y asistimos como lectores al acto de creación de lo que leemos; es decir, a un asentamiento por escrito de un relato fuente oral, en una reedición de la tarea de "traducción" cultural del antropólogo con sus informantes nativos.

De hecho, Blue Marrow puede verse en este doble movimiento "traductor": como textualización de la enunciación oral y como oralización del texto a través del que, a fin de cuentas, nos llega la obra. ${ }^{7}$ En este último sentido, al dotar al texto escrito de características orales que atentan contra su fijeza y normatividad, la autora opone resistencia a los actos de dominación acarreados por la inscripción: la letra de los tratados que despojaron a los nativos norteamericanos de sus tierras y la colonización espiritual con la imposición de las sagradas escrituras judeocristianas.

No sorprende entonces que un poema como Blue Marrow, de naturaleza contaminada y subversiva, inter-media, se rehúse a un ordenamiento rígido en patrones de pies y metros. ${ }^{8}$ La impronta oral cala su lírica con la libertad del discurso fluido que no quiere ceñirse al claustro "colonial" de la escritura. La soltura de la alternancia de códigos se reproduce también en la transición entre verso y prosa poética ${ }^{9}$ en pasajes continuos, como la descripción inicial de las abuelas.

7 Lee Maracle prefiere adaptar el término "oratoria" (oratory) para referirse a la representación escrita del discurso oral en las literaturas indígenas y distinguirlas de la tradición letrada de las culturas hegemónicas. En cuanto a las tradiciones orales, líricas o narrativas, vale la pena también tener en cuenta los términos "oratura" (orature) que desde los estudios poscoloniales manejan intelectuales como Ngũgĩ wa Thiong'o y Pio Zimiru para referirse a las literaturas orales africanas, y "oralitura". Véase, respectivamente, Thomas H. Jackson (1991) y Olga Vallejo (2008).

8 La estructura formal tradicional del verso en inglés se mide, en general, en pies poéticos, que son unidades compuestas por dos o más sílabas tónicas o átonas. La métrica cuantifica los pies que contiene un verso o línea del poema. Así, por sólo citar un ejemplo, un pentámetro yámbico es un verso formado por cinco yambos (pies constituidos por una sílaba átona seguida por una tónica).

9 El cambio de prosa a verso, con la partición de las líneas, se da entre la primera y la segunda edición de Blue Marrow, como observa Mareike Neuhaus: "With the addition of line breaks, some of the poetic prose of the first edition turns into free verse poems [...]" (Neuhaus, 2011: 180). 
Para Cook "this free verse invocation emerges from the structure of the prose poem portraits that have preceded it as if squeezed out of alignment by the pressure of memory and the force of obligation" [esta invocación en verso libre surge de la estructura de los retratos en prosa poética que la anteceden, como si la presión de la memoria y la fuerza de la obligación le hubieran hecho desarticular la alineación] (Cook, 2000: 8).

Por su parte, el tercer poemario de Halfe, The Crooked Good, es una síntesis formal de los dos primeros libros, pero esta vez parte de una historia mítica que cuenta la madre narradora, aspin, junto al fuego en las noches de invierno. La voz lírica del personaje Turn-Around Woman participa en una colección de poemas independientes como en Bear Bones..., pero engarzados ahora por personajes que reaparecen una y otra vez, como en Blue Marrow, para propiciar el retrato familiar y el origen de una cultura mestiza. Nuevamente se sitúa a la mujer (rebelde, amante, madre) en el vértice de la atención. El libro recupera de Blue Marrow, además, las marcas tipográficas y las transiciones de voces.

En sus tres libros, Halfe comunica una identidad inalienablemente híbrida que hace de la experimentación literaria un arma de resistencia. Penny Petrone explica cómo ha funcionado esta hibridez en la literatura nativa:

"It bounds 'the sacred and the profane, the individual and the tribal, the past, present and future, and it encompasse[d] the teller, the listener, the tribe, and the land, and the universe'. By transmitting specific cultural knowledge, with its specific meaning and messages, it helped strengthen tribal identity and provided for its continuity" [Une "lo sagrado y lo profano, lo individual y lo tribal, el pasado, el presente y el futuro y envolvía al narrador oral, al oyente, a la tribu, la tierra y el universo". Al transmitir un conocimiento cultural específico, con sus significados y sus mensajes específicos, contribuía a fortalecer la identidad tribal y aseguraba su continuidad] (Harmut Lutz, en Petrone, 1990: 4).

El ser subalterno reafirma su capacidad proteica; es decir, la proyección contradiscursiva de estos textos no sólo descansa en los contenidos históricos erigidos desde nuevas perspectivas, sino en los recursos formales que desarticulan el enunciado monolítico dominante. En palabras de Barbara Godard:

\footnotetext{
“'Heterogeneity', fractured genres, 'polimorphous' subjects, 'borderland' sites - these are marks of 'resistance writing' especially as practised by Native North American under 'métissage' in their within/ without relation to the dominant social formations" [La "heterogeneidad", los géneros fracturados, los temas "polimorfos", los espacios "fronterizos" todas estas son marcas de "escritura de resistencia", en especial como las desarrollan los escritores nativos de Norteamérica que viven en situación de mestizaje en su relación dentro/fuera de las formaciones sociales dominantes] (Godard, 1990: 198).
}

De los tres cuadernos, podría afirmarse que Blue Marrow es el más atípico y el que lleva la hibridez textual a un grado superior. No basta decir, sin embargo, que éste ha sido el libro más "rebelde" de la poeta contra el discurso y la institución literaria convencionales. Habría que aclarar que, sobre todo, lo fue su primera edición, publicada por McClelland \& Stewart en 1998. 
El brusco salto que se produce desde Bear Bones..., donde ya la autora diseminaba voces crees en el interior de sus poemas en inglés, radica en que la edición de 1998, por una parte, se atreve a prescindir de un glosario cree-inglés $\mathrm{y}$, por otra, desde el punto de vista formal capta la hibridez de la zona de contacto colonial borrando las fronteras entre voces y tiempos. Halfe propicia la interacción y el dialogismo de sus personajes sin marcar la transición entre ellos, lo que ciertamente demanda un gran esfuerzo del lector no nativo, de por sí enfrentado a un universo ajeno. Sobre la ausencia de glosario, apunta Méira Cook: "This purposeful omission is an editorial choice that signals her acknowledgement that she is not writing predominatly for a white Englishspeaking audience" [Esta omisión intencionada es una decisión editorial con la que la autora indica que no escribe principalmente para un público lector anglófono y blanco] (Cook, 2000: 93). Este planteamiento recuerda a Samia Mehrez en su concepción de que las literaturas poscoloniales excluyen al lector monolingüe $\mathrm{y}$ "demand of their readers to be like themselves: 'in between,' at once capable of reading and translating, where translation becomes an integral part of the reading experience" [requieren que sus lectores sean como ellos mismos: "inter-medios", capaces de leer y traducir al mismo tiempo, y la traducción se vuelve una parte esencial de la experiencia de lectura] (Mehrez, 1992: 122).

Sin embargo, en la edición revisada de Coteau Books, seis años más tarde, se incorporan un glosario para las voces crees y algunos cambios internos del poema, que incluyen la identificación del sujeto lírico de modo semejante a la indicación de personajes en el teatro en verso. Al pulir su "otredad", la autora acerca su segunda versión a las normas de aceptación editorial, como describe Mareike Neuhaus: "The identification of voices in the form of short indented paragraphs, however, makes the revised edition of Blue Marrow more reader friendly" [La identificación de voces a través de párrafos cortos sangrados logra, no obstante, que la edición revisada de Blue Marrow sea más sencilla para los lectores] (Neuhaus, 2011: 180).

Ahora bien, si es cierto que funcionan como premisas universales que cada traducción parte de una interpretación personal, y que la localización histórica y cultural del sujeto que la lleva a cabo son determinantes, podemos aplicarlas con mayor razón en el caso de una obra bastante enigmática ya desde la lengua de partida. Su hermetismo propicia así la función creativa de la traducción pilar clave de la agenda traductológica feministay su papel activo en la construcción de formas y sentidos. Basada en los rasgos estilísticos de Halfe y en su uso subversivo de la lengua, me detengo a continuación en las principales consideraciones teóricas que sustentan una propuesta de traducción seguidora de los presupuestos ideológicos de Blue Marrow.

\section{TRADUCIR BLUE MARROW} DESDE UNA AGENDA FEMINISTA

Los rasgos de la obra de Halfe permiten respaldar su traducción con teorías feministas ligadas a la disciplina (en particular aquellas lideradas por las academias canadiense y estadounidense). Un 
texto como Blue Marrow donde, por una parte, los personajes femeninos son centrales en la historia y en el discurso y, por otra, se potencia la creatividad lingüística a través de las continuas experimentaciones de la autora, brinda el terreno propicio para llevar a cabo una traducción que refuerce y visibilice el papel activo de la traductora en la creación de sentidos; una traducción que extienda el sentido liberador y subversivo del texto fuente hacia la reivindicación creativa del proceso de transposición lingüística. Además, el texto de Louise Halfe explicita su conciencia lingüística y su voluntad de registrar la presencia femenina mediante el extrañamiento de la lengua a partir, por ejemplo, de la sexualización de elementos naturales, a pesar de que por su empleo del género gramatical "natural", la lengua inglesa se considera más neutral ${ }^{10}$ en la calificación de sustantivos y adjetivos que las lenguas romances.

Sherry Simon reconoce la analogía entre lo femenino y la traducción al sostener que "the femineity of translation is a persistent historical trope" [la femineidad de la traducción es un tropo histórico recurrente] (Simon, 1996: 1). Al igual que Lori Chamberlain, Simon comprende la relación de estos ámbitos a partir de la condición de inferioridad que ha pesado tanto sobre la mujer como sobre la traducción — con respecto a una autoridad masculina atribuible a un "original” - en el discurso tradicional a lo largo de los años. La coincidencia temporal de un auge en los estudios traductológicos y los de género, así como la pertinencia de la conciencia lingüística y de identidad en la agenda de estos últimos bajo

10 Sherry Simon plantea, sin embargo, que esta "neutralidad" es sólo aparente (1996: 19). el amparo de los estudios culturales, han permitido asimismo una interconexión entre ambos campos (y sus protagonistas) propiciando la reflexión de Simon: "it is hardly surprising that translation studies should be nourished in important ways by feminist thought" [no sorprende que el pensamiento feminista haya nutrido de modo considerable la disciplina de la traductología] (Simon, 1996: 8).

El pensamiento feminista, en su consideración del acto traductor como creación de sentidos y, en definitiva, como escritura, contribuye a difuminar los límites entre original y traducción, finalmente, dicotomías maniqueas que responden a una visión conservadora de la disciplina. Susan Bassnett, por ejemplo, argumenta:

\footnotetext{
"the idea that translation is somehow a secondary activity, inferior to the act of writing, that the translation stands lower in the hierarchy than the privileged 'original' is rejected in favour of a notion that sees translation and writing as interconnected, with the one assuring the survival of the other" [las ideas de que la traducción es de cierto modo una actividad secundaria, inferior al acto de escritura, y de que la traducción tiene un nivel más bajo en la jerarquía que privilegia el "original", se desechan en favor de una noción que considera la traducción y la escritura como actividades interconectadas, donde una garantiza la supervivencia de la otra] (Bassnett, 1992: 65).
}

La traductora que trabaja con un texto generado bajo los postulados feministas de su autora desmantela la ilusión de la equivalenciatransparencia que subyace tras una concepción de imparcialidad comunicativa, para asumirse a sí misma (y a su labor translaticia) como generadora de nuevos significados en un proceso de reescritura 
más que de simple reproducción o mediación automática. El ejercicio traductor se baña de las connotaciones reivindicativas que se aplican a la mujer y se desvanece todo su aparente silencio o ilusoria pasividad. Así, la agenda feminista extiende sus luchas de género al campo de la traducción, liberando a la figura traductora de su vasallaje absoluto ante la autoral (la autoridad), y se alinea apasionadamente con la perspectiva contestataria a la corriente traductológica tradicional, como explica Solange Mittmann en Notas do tradutor e proceso tradutório. Es decir, rechaza la idea de que el original tenga un sentido unívoco, acorde con las intenciones autorales y transportable fiel y transparentemente por el o la traductora. Frente a ella, se atribuye a los traductores la cualidad de productores y responsables de los sentidos creados en su tarea, a partir de "nas tomadas de posição, tanto na escolha do texto a ser traduzido como a cada escolha entre opções durante a tradução" [las tomas de posición, tanto en la elección del texto que se va a traducir como en cada elección entre distintas opciones durante el proceso de traducción] (Mittmann, 2003: 29).

La corriente feminista, como parte de las "contestatarias", aprecia la tarea de traducción como una sucesión de ejercicios de lectura y de posterior recomposición del mensaje, irreductiblemente parcializados por sus contextos de producción y recepción y por la ideología de quien traduce. Para Simon: "Translation is considered as a mode of engagement with literature, as a kind of literary activism $[\ldots]$ Translators are necessarily involved in a politics of transmission, in perpetuating or contesting the values which sustain our literary culture" [La traducción se considera como un modo de compromiso con la literatura, una especie de activismo literario (...) Los traductores están involucrados en una política de transmisión, en perpetuar u oponerse a los valores que sostienen nuestra cultura literaria] (Simon, 1996, vIII).

La asunción feminista de la traducción apela a una posición ética de compromiso con el texto que se trabaja y también, en sentido amplio, con la tradición literaria en la que éste se inserta. Se crea un vínculo que transita entre lo intelectual y lo emocional: "[translators] are fully invested in the process of transfer" [los traductores se consagran totalmente al proceso de transferencia], afirma Simon (1996: 5); "the translator must surrender to the text" [el traductor tiene que rendirse ante el texto], añade Spivak (2012: 316).

Simon plantea, finalmente, que una vez comprendido el proyecto creativo de la autora a quien se traduce, la traductora ha de aplicar sus premisas al suyo propio basándose en una nueva concepción de fidelidad ("For feminist translation, fidelity is to be directed toward neither the autor nor the reader, but toward the writing project — a project in which both writer and translator participate") [Para la traducción feminista, la fidelidad no se dirige al autor ni al lector, sino al proceso de escritura - un proyecto en el cual participan tanto escritores como el traductores] (Simon, 1996: 2). De manera que la agenda feminista de la traducción implica, más que un arte o un oficio, una militancia consciente en la tarea de lectura y reescritura.

Comprendemos, como Sherry Simon, que la intervención textual del feminismo evita desviar una obra de su intención original: "Feminist translation 
implies extending and developing the intention of the original text, not deforming it" [La traducción feminista implica expandir y desarrollar la intención del texto original, no deformarla] (Simon, 1996: 16). Es por este motivo que en realidad la traducción feminista cobra sentido cuando presenciamos una obra cuyos presupuestos incendiarios, como en el caso de Halfe, pueden ser compartidos y extendidos por quien la lleve a cabo, consciente del poder evocador de la lengua y de la responsabilidad ética en la recomposición de significados que tiene quien traduce. Es decir, "[...] the project of the feminist translator concords with the impulse of the text, questioning the most basic relationship of word to object, word to emotion, word to word" [el proyecto de la traductora feminista concuerda con el impulso del texto, cuestionando la relación más básica de la palabra con el objeto, de la palabra con la emoción, de la palabra con la palabra] (Simon, 1996: 27). En nuestro caso, la capacidad de maniobra impulsada por la traductología feminista busca resaltar los rasgos que Halfe trabaja ostensiblemente en su texto: la polifonía, la oralidad y la figura de la mujer.

Pero las reflexiones sobre la agencia traductora $\mathrm{y}$, por consiguiente, de sus implicaciones políticas, no se generan exclusivamente desde el lente feminista de la traductología. Si, como hemos dicho, los estudios culturales han interconectado múltiples campos del conocimiento al analizar los fenómenos sociales y discursivos como entidades contaminadas y dinámicas, no han de sorprendernos los vasos comunicantes entre estudios de género y poscoloniales aplicados a la tarea de traducción. De hecho, traductoras y traductólogas como Lori Chamberlain, Barbara Godard, Sherry Simon y
Susan Bassnett, pueden hallarse como analistas de uno y otros campos, al punto de desdibujar la frontera académica de este triángulo de perspectivas.

La obra de Halfe abre entonces el camino a una tarea de traducción que sincroniza la conciencia de género con la racial e, incluso, con la socioeconómica.

\section{MIRADAS POSCOLONIALES}

Podríamos entender a Louise Halfe como escritora poscolonial en la medida en que reflexiona sobre los efectos de la colonización en la cultura autóctona a la que pertenece. Al describir en inglés - lengua de la antigua metrópoli - un universo ajeno y periférico como es el mundo referencial cree, la poeta se coloca en un lugar de "mediación" equivalente al de una traductora. Como los mediadores lingüísticos, que cabalgan entre el sistema cultural de partida y el de llegada, la escritora poscolonial - en general plurilingüe - se mueve entre los códigos de su cultura nativa y aquella de la antigua metrópoli. Samia Mehrez, para quien la creación y la lectura del texto poscolonial implican ya una experiencia de traducción, "In effect, this literary production is in and of itself plurilingual [...]" [Efectivamente, esta producción literaria es en sí y por sí misma plurilingüe] (Mehrez, 1992: 122). La estudiosa también reúne en una sola entidad a lectores poscoloniales y traductores ("reader/translator") (Mehrez, 1992: 123).

La traducción, íntimamente ligada a los sistemas culturales y atravesada por sus tensiones, debe verse en su naturaleza creadora —al igual que cualquier otra forma de escritura- y desestabilizadora de límites, de modo que sacude 
relaciones de poder y jerarquías, cuestiones tan centrales en el pensamiento poscolonial como en el feminista. En este sentido, Lori Chamberlain plantea la capacidad intrínsecamente perturbadora del acto traductor: "I would argue that the reason translation is so overcoded, so overregulated, is that it threatens to erase the difference between production and reproduction which is essential to the establishment of power" [Yo afirmaría que el motivo por el cual la traducción se ha codificado y regulado tanto, es que amenaza con borrar esa diferencia entre producción y reproducción que es fundamental para el establecimiento del poder] (Chamberlain, 1992: 66).

Ya sea en el ámbito de los estudios poscoloniales y feministas como de la traducción, el contacto híbrido entre varios sistemas deviene foco de atención: "The hierarchies of writing roles, like gender identities, is increasingly to be recognized as mobile and performative. The interstitial now becomes the focus of investigation, the polarized extremes abandoned" [Las jerarquías de los roles de la escritura, como las identidades de género, cada vez más se reconocen como móviles y performativas. El intersticio se vuelve ahora centro de investigación y se abandonan los extremos polarizados], plantea Simon (1996: 12-13).

Por su parte, Maria Tymoczko reconoce que los escritores poscoloniales transponen una cultura al tiempo que los traductores un texto; no obstante, la tradición de los primeros, como podemos apreciar en Louise Halfe, actúa como un "metatexto" que se reescribe en la creación literaria, sobre todo cuando ésta ocurre en una lengua hegemónica, generalmente la de la metrópoli, donde se vierte un "contenido extraño" que desafía los moldes convencionales:

"The culture or tradition of a post-colonial writer acts as a metatext which is rewritten - explicitly and implicitly, as both background and foreground - in the act of literary creation. The task of the interlingual translator has much in common with the task of the post-colonial writer; where one has a text, however, the other has the metatext of culture itself" [La cultura o la tradición de un escritor poscolonial actúa como un metatexto que se reescribe - explícita e implícitamente, en un segundo y en un primer plano- en el acto de creación literaria. La tarea del traductor interlingüístico tiene mucho en común con la del escritor poscolonial: si aquél tiene un texto, éste tiene el metatexto de la cultura en sí] (Tymoczko, 1999: 21).

En general, tanto los escritores poscoloniales como los traductores se hallan ante la disyuntiva de presentar ante una nueva audiencia un conjunto de elementos poco familiares; es decir, una "otredad". Cuando esta entidad "otra" (la cultura cree en el caso particular de Halfe) proviene de un universo oral, la propia fijación a la escritura es ya, como hemos visto, una "traducción cultural". Hay que notar, sin embargo, que el hecho de que Halfe potencie la ambigüedad de ciertos pasajes, mantenga zonas oscuras, imágenes incomprensibles y desmonte la sintaxis, nos habla de su interés en un reconocimiento de la diferencia. $\mathrm{Su}$ "traducción" cultural no aplana los sentidos ante los lectores anglófonos; en realidad tira de ellos para alertarlos sobre un mundo referencial y expresivo ajeno.

Quien traduce literatura poscolonial está bajo la misma bandera que enarbola el análisis 
feminista: no puede menos que reconocer su responsabilidad e involucrarse en textos de patente intención política donde sobresalen diferentes texturas. No sólo se trata entonces de respetar el sello identitario de cada texto, la particular otredad de uno respecto de otro; sino un caso como el de Halfe, se complejiza con la pluralidad orquestada de voces que coexiste en el interior de un solo texto poscolonial.

En Halfe, esta polifonía ocurre prácticamente en todos los niveles de la lengua. El académico David Gaertner, por ejemplo, ha atendido las relaciones de tensión entre los códigos lingüísticos que cohabitan en el poema Blue Marrow: "Halfe, like her Grandmothers before her, must 'learn to ride English'. She must use it as a vehicle to communicate her Cree self, while still traversing the transient border separating Cree and colonial cultures" [Halfe, como había ocurrido antes con sus abuelas, tiene que "aprender a cabalgar el inglés". Tiene que usarlo como medio para comunicar su ser cree, mientras traspasa la tenue frontera que separa la cultura cree de la colonial] (Gaertner, 2007: 21-22).

Integrando, por una parte, la teoría literaria de Mijaíl Bakhtin sobre la polifonía y la hibridez literaria y, por otra, la concepción de Homi Bhabha de un tercer espacio, Michaela Wolf retoma la noción de "hibridez" como elemento primario en el terreno poscolonial que podemos asociar con la obra de Halfe. La hibridez en el campo de la lengua tiene que ver con la superposición de voces, la subversión opuesta a un discurso autoritario que es, por naturaleza, unívoco:
"In a colonial context, cultural hybridity is produced at the moment of the colonial encounter, when self and other are inseparable from mutual contamination by each other. The colonial encounter is therefore embedded a priori in power relations, and requires constant awareness of the limits and possibilities of representation" [En un contexto colonial la hibridez cultural se produce en el momento del encuentro colonial, cuando el ser y el otro son inseparables de su contaminación mutua. Por lo tanto, el encuentro colonial está inserto a priori en relaciones de poder y necesita una conciencia constante de los límites y las posibilidades de representación] (Wolf, 2000: 134).

En Blue Marrow, la coexistencia de discursos no queda únicamente en un plano teórico, y ni siquiera en la patente alternancia de códigos entre el cree y el inglés (manejados como Creeaccented English y Creenglish), ${ }^{11}$ sino hay una voluntad activa de la autora de mostrar un texto contestatario, de límites discursivos evanescentes, donde hibridez y polifonía adquieren el estatus de dialogismo y, con él, se enfatiza la relación de la una (la hablante) con el otro; es decir, en definitiva, se reconoce la "otredad" que, remitiéndonos a Bakhtin está contenida en la propia definición de dialogismo:

\footnotetext{
"Each rejoinder, regardless of how brief and abrupt, has a specific quality of completion that expresses a particular position of the speaker, to which one may respond or may assume, with respect to it, a responsive position [...] These relations are possible only among utterances of different speech subjects; they presuppose other (with respect to the speaker) participant in speech communication" [cada réplica, sin importar lo breve o abrupta que sea, tiene una
}

11 Véase Armstrong y Grauer (2001: 240) y Neuhaus (2011: $180)$, respectivamente. 
cualidad específica de entidad concluida que expresa una posición particular del hablante, ante la cual se puede responder o se puede asumir una posición receptiva (...) Estas relaciones se hacen posibles solamente por medio de los discursos de diferentes sujetos; presuponen otro (en relación con el hablante) participante en la comunicación discursiva] (Bakhtin, 1986: 72).

En presencia de una alternancia dialógica de sujetos líricos que polemizan o se complementan, el texto de Halfe se resiste a una propuesta literaria uniforme e irrebatible que formularía el ser dominado como una venganza igual de axiomática que la versión hegemónica de la historia. En el caso de nuestra autora, por el contrario, cada participante del pasado canadiense tiene derecho a la palabra, porque de cada uno ha dependido una dosis del estado actual de las cosas. La propuesta de Halfe posiciona al sujeto marginado en diálogo con el dominante para trazar una lógica alternativa que Barbara Godard explica como:

"[...] a logic grounded not on the binary codes of the law of the excluded middle, but in the logics of relativity or catastrophe theory with their serial or multiple interactions, their theorizing of chaos. This will open up a view of discourse as a field of contesting knowledges rather than as monolithic, totalitarian imposition of the Law" [(..) una lógica no basada en los códigos binarios de la ley que excluye la opción del medio, sino en la lógica de la relatividad o la teoría de la catástrofe con sus interacciones seriales o múltiples, su teorización del caos. De ese modo se da paso a una visión del discurso como un campo de saberes en tensión más que como una imposición monolítica y totalitaria de la Ley] (Godard, 1990: 195).
La lectura del poema de Halfe, por su vocación política, debe tener en cuenta el desmontaje de las relaciones de dominación en un universo jerarquizado que ha mantenido a las culturas y las identidades de género subalternas al margen del dictamen hegemónico. Como hemos visto, en su caso no funciona un antiimperialismo que en nombre del nacionalismo o del orgullo étnico desplace a las identidades subalternas de sus antiguas periferias a centros excluyentes, como han hecho algunos intelectuales nativos que vuelcan su contradiscurso hacia un pasado precolonial idealizado y prístino, olvidando, como afirma Fanon, que "the creation of culture in colonized space often involves techniques and languages 'borrowed' from the colonizer" [la creación de la cultura en el espacio colonial casi siempre incluye técnicas y lenguas "prestadas" por el colonizador], (citado por Tejaswini Niranjana, 1992: 168) y que "the universalizing move, which is, after all, part of the West's constitution of itself as subject, contributes to erasing the violence of colonialism" [la jugada universalizadora que, después de todo, forma parte de constitución de Occidente de sí mismo como sujeto, contribuye a borrar la violencia del colonialismo] (citado por Niranjana, 1992: 164). Niranjana suma sus argumentos contra purismos infértiles, al reconocer que: "Both the nationalist and the nativist discourses converge, therefore, in an acceptance of the paradigm of representation provided by the colonizing culture" [Tanto los discursos nacionalistas como los nativistas coinciden, sin embargo, en la aceptación de un paradigma de representación que aporta la cultura colonizadora] (Niranjana, 1992: 164). 
Quizá por ese motivo habría que iluminar la obra de Halfe con la variante poscolonial encauzada por el pensamiento de Homi Bhabha y los conceptos del posestructuralismo, debido a su cuestionamiento de los "centros" donde quiera que estén. El arma principal de Halfe como autora poscolonial y como mujer es su subversión de los modos dominantes de representación, la reescritura de la historia que evidencia la hibridez y las tensiones de género, raza y clase en la zona de contacto. Por lo tanto, cuando Jeannette Armstrong y Lally Grauer afirman que en la obra de Halfe "native women and men interweave their voices to form an alternative history to nonNative fur trade histories" [mujeres y hombres nativos entretejen sus voces para formar una historia alternativa a las historias no nativas del comercio de pieles] (Armstrong y Grauer, 2001: 240), esta "alternativa" está, sobre todo, en desestabilizar un recuento monotonal.

A partir del propio sentido del dialogismo en Halfe, gesto de rebeldía y liberación, y como clamor estético contra toda dominación, la traducción de Blue Marrow que propongo persigue atender los cambios de voz y recodificar la intervención de cada personaje de manera perceptible; así como enfatizar, como plantea Homi Bhabha, el valor de la hibridez del texto en tanto subversión de las relaciones coloniales de poder:

"Hybridity is the sign of the productivity of colonial power, its shifting forces and fixities; it is the name for the strategic reversal of the process of domination through disavowal (that is, the production of discriminatory identities that secure the 'pure' and original identity of authority)" [La hibridez es la evidencia de la productividad del poder colonial, sus fuerzas cambiantes y estáticas: es el nombre que toma la inversión estratégica del proceso de dominación a través de la negación (es decir, la producción de identidades discriminatorias que aseguran la identidad "pura" y original de la autoridad)] (Bhabha, 1985: 154, citado por Niranjana, 1992: 45).

En sintonía con una agenda poscolonial, también la oralidad es un rasgo pertinente, como hemos enfatizado. Para los estudios poscoloniales la oralidad representa el saber ancestral, la interacción comunitaria, el color local, la resistencia ante la tecnología arrasadora y la globalización.

La naturaleza oral de una lengua define, por lo tanto, una cosmovisión que la escuela poscolonial comparte y promueve. En su reconocido título Oralidad y escritura. Tecnologías de la palabra, Walter Ong establece las diferentes cualidades del pensamiento oral y el escrito, y cómo las culturas moldean su subjetividad y capacidad de comunicación en dependencia de sus sistemas de aprendizaje y memorización. ${ }^{12}$ La organización de las culturas orales en torno al ser humano, la valoración de la vida comunitaria y de los ancianos como depositarios del conocimiento son principios enaltecidos en Blue Marrow por medio de esta comunicación de las abuelas con las nietas. De ahí que no sólo por los rasgos sonoros del poema, sino también por su apego temático a los valores culturales crees, uno de mis móviles traductológicos consista en rescatar la oralidad en el texto meta.

12 Para Ong, "las personas que han interiorizado la escritura no sólo escriben, sino también hablan con la influencia de aquélla, lo cual significa que organizan, en medidas variables, aun su expresión oral según pautas verbales y de pensamiento que no conocerían a menos que supieran escribir" (Ong, 1987: 61). 


\section{REFLEXIONES FINALES}

El camino por recorrer en la traducción de la obra de Louise Halfe es vastísimo e incita innumerables lecturas. Sin embargo, no debe olvidarse que uno de los mayores compromisos que pueden establecerse con literaturas poscoloniales y feministas (o legibles como tales desde nuestro contexto de recepción) es el de respetar su "soberanía" textual. El acto traductor pone a prueba el imperialismo cultural $\mathrm{y}$, como afirman Lawrence Venuti y Pascale Casanova, ${ }^{13}$ el desbalance del inglés sobre otras lenguas en el panorama contemporáneo.

La primera reacción de una traductora (en este caso lo aplico a mí misma) que pretenda hacer eco, por medio de su labor, del derecho y la necesidad de las voces subalternas de hacerse escuchar, de la experiencia de rebeldía que implica el propio acto de creación contra un statu quo hegemónico, es evitar ceder ante concesiones con lectores privilegiados y mantenerlos en su zona de confort y de entendimiento. Todo lo contrario, se trata de llamarles la atención hacia la diferencia, hacia la cultura otra que clama por su lugar en el mundo.

Reconocemos, sin embargo, que la “extranjerización" ${ }^{14}$ como estrategia elegida nunca puede ser plena aun cuando medie una asunción ética. La complejidad del texto poético, donde son tan importantes el mensaje y las imágenes como los recursos sonoros, pone en evidencia que la tarea traductora es un apasionante proceso de continuas búsquedas y elecciones.

Queda entonces en nuestras manos blandir las banderas que con ellas sostenemos, y cerrar filas en esta aventura de lograr que la literatura trascienda las fronteras y que otra mujer de un pueblo originario de nuestro continente sea escuchada en español.ð

13 Véase Lawrence Venuti (1995) y Pascale Casanova (2010: 285-303).

14 "Foreignizing translation signifies the difference of the foreign text, yet only by disrupting the cultural codes that prevail in the target language" (Venuti, 1995: 20). 


\section{BIBLIOGRAFÍA}

Armstrong, Jeannette y Lally Grauer (eds.) (2001), Native Poetry in Canada: A Contemporary Anthology. Peterborough, Broadview Press.

Bakhtin, Mikhail Mikhalovich (1986), Speech Genres and Other Late Essays (trad. Vern W. McGee). Texas, University Press.

Bassnett, Susan (1992), “Writing in No Man's Land: Questions of Gender and Translation”, en Ilha do Desterro, núm. 28, pp. 63-73.

Bhabha, Homi (2002), El lugar de la cultura (trad. César Aira). Buenos Aires, Manantial.

Casanova, Pascale (2010), "Consecration and accumulation of Literary Capital: translation as unequal Exchange”, en Mona Baker (ed.), Critical Readings in Translation Studies (trad. Siobhan Brownlie). London y New York, Routledge, pp. 285-303.

Chamberlain, Lori (1992), "Gender and the Metaphorics of Translation", en Lawrence Venuti (ed.), Rethinking Translation: Discourse, Subjectivity, Ideology. London y New York, Routledge, pp. 314-329.

Cook, Méira (2000), "Bone Memory. Transcribing Voice in Louise Bernice Halfe's Blue Marrow", en Canadian Literature, núm. 166, pp. 85-110.

Gaertner, David (2007), “Writing with Blood: Dis-covering Essence in Louise Bernice Halfe's Blue Marrow". Winnipeg, Universidad de Manitoba, tesis de maestría.

Godard, Barbara (1990), “The Politics of Representation. Some Native Canadian Woman Writers", en William Herbert New (ed.), Native Writers and Canadian Writing. Vancouver, University of British Columbia.

Gunn Allen, Paula (1989), Spider Woman's Granddaughters. Traditional Tales and Contemporary Writing by Native American Women. Boston, Beacon Press. 
Halfe, Louise Bernice (1994), Bear Bones and Feathers. Regina, Coteau Books.

Halfe, Louise Bernice (1998), Blue Marrow. Toronto, McClelland \& Stewart.

Halfe, Louise Bernice (2007), The Crooked Good. Regina, Coteau Books.

Jackson, Thomas H. (1991), "Orality, Orature, and Ngũgĩ wa Thiong'o", en Research in African Literatures, vol. 22, núm. 1, pp. 5-15.

Jolly, Joanna (2015), “El macabro misterio de las mujeres de Río Rojo del Norte”, en BBC Mundo, 19 de abril de 2015, URL: http://www.bbc.co.uk/mundo/noticias/2015/04/150416_misterio_macabro_rio_ rojo_finde_dv

Manossa, Geraldine (2002), The Roots of Cree Drama. Universidad de Lethbridge, tesis de maestría.

Mehrez, Samia (1992), "Translation and the Post-Colonial Experience", en Lawrence Venuti (ed.), Rethinking Translation: Discourse, Subjectivity, Ideology. London y New York, Routledge, pp. 120-137.

Mittmann, Solange (2003), Notas do tradutor e proceso tradutório. Análise e Reflexão sob uma Perspectiva Discursiva. Porto Alegre, Editora da Universidade Federal do Rio Grande do Sul.

Neuhaus, Mareike (2011), That's Raven Talk: Holophrastic Readings of Contemporary Indigenous Literatures. Regina, Canadian Plains Research Center, University of Regina.

Niranjana, Tejaswini (1992), Siting Translation: History, Post-structuralism, and the Colonial Context. Berkeley y Los Angeles, University of California Press.

Ong, Walter (1987), Oralidad y escritura. Tecnologías de la palabra (trad. Angélica Scherp). México, Fondo de Cultura Económica.

Petrone, Penny (1990), Native Literature in Canada. From the Oral Tradition to the Present. Toronto, Oxford University Press. 
Simon, Sherry (1996), Gender in Translation. Cultural identity and the politics of transmission. London y New York, Routledge.

Smith, Shannon (s/f), "Native storytellers connect the past and the future", en Native Daughters, consultado el 15 de enero de 2015, URL: http://cojmc.unl.edu/nativedaughters/storytellers/nativestorytellers-connect-the-past-and-the-future

Spivak, Gayatri Chakravorty (2012), “The politics of translation”, en Lawrence Venuti (ed.), The Translation Studies Reader. London y New York, Routledge, pp. 397-416.

Stigter, Shelley (2006), "The Dialectics and Dialogics of Code-Switching in the Poetry of Gregory Scofield and Louise Halfe”, en American Indian Quarterly, vol. 30, núm. 1/2, pp. 49-60.

Tymoczko, Maria (1999), "Poscolonial writing and literary translation", en Susan Bassnett y Harish Trivedi (eds.), Post-colonial Translation: Theory and Practice. London y New York, Routledge.

Vallejo, Olga (2008), "Oralitura y tradición oral”, en Diccionario electrónico de la literatura colombiana, disponible en http://ihlc.udea.edu.co/delc/index.php?tema=546.

Venuti, Lawrence (1995), The Translator's Invisibility. A History of Translation. London y New York, Routledge.

Wolf, Michaela (2000), "The Third Space in Postcolonial Representation”, en Sherry Simon y Paul StPierre (eds.), Changing the Terms: Translating in the Postcolonial Era. Ottawa, University Press.

Fecha de recepción: 14 de febrero de 2015

Fecha de aceptación: 15 de mayo de 2015 